\title{
New treatments for catatonia not being part of schizophrenia-case report
}

\begin{abstract}
Some patients with psychotic features seem refractory to psychotherapeutic or psychopharmacological interventions after substance abuse related problems are excluded as an explanation. We present a patient who at the age of 20 developed several schizophreniform symptoms. Seizure like symptoms also developed during a stay in the acute ward. He was treated with several antipsychotics, but did not improve much after several referrals to the acute care unit. A lorazepam provocation test was performed. In the ensuing hours, his aggressiveness and nonsense speaking rapidly diminished. Kahlbaum's observation of seizures as part of a catatonia was not understood in this case.1 The publication of the new DSM-V diagnosis of catatonia may hopefully reduce the probability of treating a patient for schizophrenia for years without access to a more targeted medication and subsequently electroconvulsive treatments. The case presents hope for some of the patient deemed refractory to conventional schizophrenia treatment schedules.
\end{abstract}

Keywords: catatonia, lorazepam, electroconvulsive treatment, schizophrenia
Volume 5 Issue 3 - 2018

\author{
John E Berg \\ Oslo Metropolitan University, Norway
}

Correspondence: John E Berg, Professor, Specialist in Psychiatry, Oslo Metropolitan University/Oslo Met, Faculty of Health Sciences, Pilestredet 48, 0130 Oslo, Norway, Tel +47 67235000/004792090438,Email john@pong.no

Received: May 22, 2018 | Published: June II, 2018

\section{Introduction}

Patients not responding to psychotropic medication are a challenge for psychiatrists and facility staff both in the substance abuse and acute psychiatry wards. It is an open question how many patients are not helped for their purported psychotic illness with antipsychotics. Ten to fifteen per cent would be a fair guess. ${ }^{2}$ When pharmacological treatment does not work for the assumed illness, clinicians look for other ways to treat. Is it possible that a psychosis does not respond to antipsychotics, or is the presumption of a psychosis wrong? If the latter is the case, giving any antipsychotic may make the patient worse or inadvertently plagued by side effects of the medication. A case involving neuroleptic malignant syndrome as a result of treating a person with catatonia with antipsychotics is reported elsewhere. ${ }^{3}$

Karl Ludwig Kahlbaum, ${ }^{1}$ published in 1874 a book on catatonia describing the diverse features of this disease, almost 40 years before Bleuler in 1911, and in 1908 in Berlin, introduced the diagnostic category of schizophrenia in a lecture in Burghölzli in Zürich. ${ }^{1} \mathrm{He}$ revised and expanded his schizophrenia concept in his seminal study of 1911, Dementia Praecox, oder Gruppe der Schizophrenien. The catatonia described by Kahlbaum, ${ }^{1}$ was disregarded as a syndrome on its own, and the main features of catatonia were included in the description of schizophrenia. Central features of catatonia were mutism, stupor, negativism, posturing (often seen also in non-treated patients with schizophrenia proper), stereotypy and mannerisms.

Some of these patients, with affective symptoms and more schizophreniform symptoms as part of the primary diagnostic entity, may be helped by electroconvulsive treatment (ECT), without suffering from schizophrenia. This was already shown in a paper penetrating the medical records of the first series of patients treated by Meduna in Budapest, albeit with camphor. ${ }^{4}$ They concluded that both continuation and maintenance electroconvulsive therapy were efficacious, safe, well tolerated, and cost-effective for patients with major psychiatric disorders with depression. The procedure in itself is deemed extremely safe according to Nuttal et al., ${ }^{5}$ who studied 2279 patients given 17,394 ECT treatments. ${ }^{5}$ No deaths were observed, and only transient cardiac complications (arrhythmias and one cardiac arrest) in 9 patients. The adverse effects of ECT are related to the anaesthesia, which today is very short and practically without any danger of mortality. In patients diagnosed as having a catatonia disorder the combination of lorazepam and ECT, is the treatment of choice. Giving antipsychotics does not help these patients. Positive clinical experience with ECT in helping patients regain an eutym state, highlights the importance of getting a written consent from the patient for the procedure. That may be a challenge, as in the patient presented below.

\section{Case}

A young man of 24 years has been referred to acute psychiatric treatment several times during the last four years. He is still living with his mother, who is very concerned about his functional setbacks. He showed all the symptoms described above both at home and during resident stays in the acute ward. The author observed that he one day could be completely mute, responding with head movements only, and the next day talking reluctantly, but coherently. He often lay in his bed with the head $15 \mathrm{~cm}$ above the cushion. Several first and second-generation antipsychotics were given as far as one could. He resisted taking them all most of the time and only during compulsory resident stays IM injections could be given, but to no avail. Clozapine treatment was contemplated as a last resort as effective antipsychotic treatment. But this treatment needs strict cooperation of the patient. He was not able to cooperate. He slept during the day and he had barely had one night in the ward without getting out of bed several times, smoking being aggressive against items in the room and the nurses.

Then a lorazepam challenging test with only $1 \mathrm{mg}$ orally was given because the department did not have injectables. ${ }^{2}$ His motor unrest and incoherent speech improved for a couple of hours. He was put 
on $2 \mathrm{mg}+4 \mathrm{mg}$ lorazepam IM regularly and on this medication, he slept during nights for the first time. There was an improvement in his behaviour and reduction in aggression. When the question of ECT was aired, he consistently refused. Although thoroughly explained and recommended he did not accept to try a series of ECT-sessions. Lorazepam did continue to keep him more stable, but we could not give him the other essential part of recommended treatment for catatonia.

\section{Discussion}

The present case demonstrates the importance of a thorough clinical diagnosis in patients with changing stupor and mutism, florid megalomanic and muscular symptoms. The seizures as observed already by Karl Ludwig Kahlbaum from 1863 may be a signal of the disease of catatonia in an early stage. ${ }^{1}$ The use of lorazepam is both a diagnostic tool and a treatment supplement besides ECT when the patient suffers from catatonia. ${ }^{6}$ Treatment with ECT over many years may influence memory and cognition, but the severity differs greatly. Malignant neuroleptic syndrome may also have developed in this patient. ${ }^{7}$ His definite improvement after ECT would be a positive input in the vivid on-going discussion by lay people and psychologist/ psychiatrists on cognitive deficits after ECT. ${ }^{8-14}$

It is still disputed in the literature, less among clinicians, whether ECT as a maintenance option is effective in severe depression or catatonia. In a prospective, controlled study Swoboda et al., ${ }^{15}$ studied a group of patients $(\mathrm{N}=42)$ with affective or schizoaffective disorder. ${ }^{15}$ They got either maintenance ECT + pharmacotherapy or pharmacotherapy alone. At 12 months, the former group had a rehospitalisation rate of $33 \%$ whereas the latter had $67 \%$. Time to relapse was also longer in the ECT group. The results were somewhat poorer for the schizoaffective cases. In a case as the present with catatonia evidence for the positive effect of ECT with or without the use of lorazepam is forthcoming.

The outcome years after a series of ECT may in many cases not be very different from other short-term treatment options as pharmacotherapy and/or psychotherapy for depressions. ${ }^{16}$ Our patients are influenced by social, economic and emotional factors after successful ECT. These factors would mostly not be related to the ECT as such. Helping patients develop skills to cope with life would be a task for other health professionals than those administering the treatment. In a small follow up study after ECT some patients committed suicide long time after the end of the series..$^{17}$ The patients had serious problems with coping in life as assessed by the Sense of Coherence test of Antonovsky. ${ }^{18}$ Long-term maintenance treatment may thus contribute to a lower mortality rate in severely depressed patients. The present patient has not as yet accepted what would most probably give him a better life. Until this happens he will be an economic burden on the treatment facilities and also a financial and emotional burden on the family. ${ }^{19,20}$ The ethical restrictions on giving the purportedly best treatment in this case is a challenge both for the family and the therapists.

\section{Acknowledgements}

None.

\section{Conflict of interest}

The author declares there is no conflict of interest.

\section{References}

1. Kahlbaum KL. Die Katatonie oder das Spannungsirresein. eine klinische Form psychischer Krankheit. Germany, Berlin, Hirschwald; 1874: $124 \mathrm{p}$.

2. Fink M, Taylor MA. Catatonia: A clinicians's guide to diagnosis and treatment. UK, Cambridge University Press. 2006: 276 p.

3. Berg JE. Lorazepam provocation test in purported schizophrenia with lack of treatment response. Ment Ill. 2014;6(2):5627.

4. Gazdag G, Baran B, Kárpáti M, et al. The history of Lipótmezö, the site of the first convulsive therapy. J ECT. 2007;23(4):221-223.

5. Nuttall GA, Bowersox MR, Douglass SB, et al. Morbidity and mortality in the use of electroconvulsive therapy. JECT. 2004;20(4):237-241.

6. Fink M. Convulsive therapy: a review of the first 55 years. $J$ Affect Disord. 2001;63(1-3):1-15.

7. Berg JE. Memory loss after electroconvulsive treatment - may the sudden alleviation of depression-inducing memories explain patient despair? Med Hypotheses. 2011;77(6):1000-10003.

8. Rose D, Fleischmann P, Wykes T, et al. Patients' perspectives on electroconvulsive therapy: systematic review. $B M J$. 2003;326(7403):1363-1368.

9. Abrams R. Does brief-pulse ECT cause persistent or permanent memory impairment? JECT. 2002;18(2):71-73.

10. Smith GE, Rasmussen KG Jr, Cullum CM, et al. A randomized controlled trial comparing the memory effects of continuation electroconvulsive therapy versus continuation pharmacotherapy: results from the Consrotium for research in ECT (CORE) study. J Clin Psychiatry. 2010;71(2):185-193.

11. Moritz S, Ferahli S, Nber D. Memory and attention performance in psychiatric patients: lack of correspondence between clinician-rated and patient-rated functioning with neuropsychological test results. $J$ Int Neuropsychol Soc. 2004;10(4):623-633.

12. Legendre SA, Stern RA, Solomon DA, et al. The influence of cognitive reserve on memory following electroconvulsive therapy. $J$ Neuropsychiatry Clin Neurosci. 2003;15(3):333-339.

13. Sackeim HA. Autobiographical memory and electroconvulsive therapy. do not throw out the baby. JECT. 2014;30(3):177-186.

14. Semkovska M, McLoughlin DM. Retrograde autobiographical amnesia after electroconvulsive therapy: on the difficulty of finding the baby and clearing murky bathwater. J ECT. 2014;30(3):187-190.

15. Swoboda E, Conca A, König P, et al. Maintenance electroconvulsive therapy in affective and schizoaffective disorder. Neuropsychobiology. 2001;43:23-28.

16. Petrides G, Fink M, Husain MM, et al. ECT remission rates in psychotic versus nonpsychotic depressed patients: a report from CORE. J ECT. 2001;17(4):244-253.

17. Berg JE. Death by suicide long after eletroconvuslive therapy. Is the sense of coherence test of Antonovsky a predictor of mortality from depression? Ment Ill. 2010;2(1):e3.

18. Antonovsky A. The structure and properties of the sense of coherence scale. Soc Sci Med. 1993;36(6):725-733.

19. Fadden G, Bebbington P, Kuipers L. Caring and its burdens. A study of the spouses of depressed patients. Br J Psychiatry. 1987;151:660-667.

20. Rice DP. The economic impact of schizophrenia. J Clin Psychiatry. 1999;60(Suppl 1):4-6. 